\title{
Pulmonary resistance and maximal expiratory flow- rates following isoprenaline in patients with chronic obstructive lung disease ${ }^{1}$
}

\author{
D. C. ST ÁNESCU, J. CLEMENT, and \\ K. P. VAN DE WOESTIJNE \\ Academisch Ziekenhuis St. Rafaël, Leuven, Belgium
}

\begin{abstract}
Stănescu, D. C., Clément, J., and van de Woestijne, K. P. (1973). Thorax, 28, 716-720. Pulmonary resistance and maximal expiratory flowrates following isoprenaline in patients with chronic obstructive lung disease. Pulmonary resistance, maximal expir atory flowrates (measured from flow-volume curves), and lung volumes were measured in 17 patients with chronic obstructive lung disease before and 20 minutes after isoprenaline aerosols. Forced vital capacity, maximum expiratory flowrates, and pulmonary resistance all changed significantly following isoprenaline. Using a discriminant analysis, we showed that the bronchodilator effect was reflected almost completely by only two indices, pulmonary resistance and maximum expiratory flowrate at $25 \%$ of the control vital capacity. The information provided by each was independent. When the change following bronchodilatation is expressed as a percentage, pulmonary resistance carried most of the information and for practical purposes this index may be used alone.
\end{abstract}

For several years airway $\left(\mathbf{R}_{\mathrm{aw}}\right)$ or pulmonary $\left(\mathbf{R}_{\mathrm{p}}\right)$ resistance was considered to be the most sensitive index in the assessment of changes in bronchial calibre following the administration of bronchomotor agents. Comparative studies of $\mathbf{R}_{\mathrm{aw}}$ and various indices measured from the expiratory spirogram showed, indeed, that the latter indices were poorer, indirect substitutes for $\mathbf{R}_{\mathrm{aw}}$ (Dautrebande, Lovejoy, and Constantine, 1960; Lloyd and Wright, 1963; Cohen and Hale, 1965; Payne, Chester, and Hsi, 1967; Weng, Featherby, Goold, and Levison, 1969). Recently, however, the use of $\mathbf{R}_{\mathrm{aw}}$ as a reference method has been challenged; it has been reported that in some circumstances changes in bronchial calibre may induce more important variations of maximal expiratory flowrates (MEFR), as measured from a flowvolume curve, than of $R_{a w}$, and that it is even possible to observe significant modifications in MEFR without measurable changes in $R_{a w}$ (Bouhuys and van de Woestijne, 1970; McFadden, Newton-Howes, and Pride, 1970).

1Supported by a grant from the Fonds voor Wetenschappelijk Geneeskundig Onderzoek

Requests for reprints: Dr. K. P. van de Woestijne, Academisch Ziekenhuis St. Rafaël, Kapucijnenvoer, 35, 3000 Leuven, Belgium
In the present study, the sensitivity of $R_{p}$ and MEFR and other indices of bronchomotor activity was investigated in a group of patients with chronic obstructive lung disease.

\section{MATERIAL AND METHODS}

An unselected group of 20 consecutive patients (inand outpatients) with chronic obstructive lung disease (Fletcher, 1959) (mean age $42 \cdot 8 \mathrm{yr}$, range 19-67; mean height $166.9 \mathrm{~cm}$, range $156-177)$ was studied. The history of bronchial obstruction was confirmed in all patients by a decreased $\mathrm{FEV}_{1} / \mathrm{VC}$ ratio (mean $50.8 \%$, range $19-69 \%$ ) and/or reduced MEFR or increased $R_{p}$ values (Table I).

$\mathrm{R}_{\mathrm{p}}$, MEFR, dynamic compliance (C dyn), forced vital capacity (FVC), and total lung capacity (TLC) were measured before and 20 minutes after the inhalation of two puffs of isoprenaline (Medihaler-iso ${ }^{\mathrm{R}}$ ). All other bronchodilator drugs were withdrawn at least 8 hours before the study.

$R_{p}$ (mean of 8 breaths) was measured at isovolume points (Frank, Mead, and Ferris, 1957), and for each patient at the same expiratory flowrate (range 0.3 $0.5 \mathrm{l} / \mathrm{sec}$ ). C dyn (mean of 8 breaths) was determined as the ratio between tidal volume and transpulmonary pressure (measured with an oesophageal balloon) between the end of expiration and the end of inspira- 
T A B LE I

MEAN VALUES AND STANDARD DEVIATIONS OF VARIOUS INDICES BEFORE AND AFTER ISOPRENALINE IN A GROUP OF 17 PATIENTS WITH CHRONIC OBSTRUCTIVE LUNG

\begin{tabular}{|c|c|c|c|c|}
\hline & & Before & After & $\mathbf{P}$ \\
\hline $\bar{R}_{\mathrm{p}}\left(\mathrm{cm} \mathrm{H} \mathrm{H}_{2} \mathrm{O} / 1 / \mathrm{sec}\right)$ & $\underset{\mathbf{S D}}{\mathbf{X}}$ & $\begin{array}{l}5 \cdot 59 \\
3.30\end{array}$ & $\begin{array}{l}3 \cdot 24 \\
2 \cdot 65\end{array}$ & $<0.001$ \\
\hline PEFR $(1 / \mathrm{sec})$ & & 4.03 & 5.01 & $<0.005$ \\
\hline MEFR $_{\text {so control }(1 / \mathrm{sec})}$ & & $\begin{array}{l}1.60 \\
1.35\end{array}$ & $\begin{array}{l}2.28 \\
2.21\end{array}$ & $<0.001$ \\
\hline MEFR $_{25}$ control $(1 / \mathrm{sec})$ & SD & $\begin{array}{l}0.85 \\
0.45\end{array}$ & $\begin{array}{l}1.62 \\
0.92\end{array}$ & $<0.001$ \\
\hline FVC (1) & SD & $\begin{array}{l}0 \cdot 34 \\
3 \cdot 678\end{array}$ & $\begin{array}{l}0.74 \\
3.990\end{array}$ & $<0.01$ \\
\hline $\mathrm{C} \operatorname{dyn}^{1}\left(1 / \mathrm{cm} \mathrm{H}_{2} \mathrm{O}\right)$ & $\hat{\boldsymbol{g}}$ & 0.133 & $0 \cdot 143$ & NS \\
\hline TLC (1) & $\begin{array}{l}\mathbf{S D} \\
\mathbf{S D}\end{array}$ & $\begin{array}{l}0.068 \\
7.017 \\
1.230\end{array}$ & $\begin{array}{l}0.062 \\
6.960 \\
1 \cdot 198\end{array}$ & NS \\
\hline
\end{tabular}

$\mathbf{P}=$ probability that the difference between the means is due to chance only: paired $t$ test.

${ }^{1}$ Mean of 16 subjects.

tion at zero mouth flow. TLC (mean of 10 measurements) and MEFR (highest value of minimum three records) were measured with a pressure corrected flow plethysmograph (Stănescu, de Sutter, and van de Woestijne, 1972). Flow-volume curves measured in the same plethysmograph were recorded on a storage oscilloscope, the thoracic gas volume (TGV) being displayed against the airflow from a heated Fleisch No. 4 pneumotachograph. From the photographed flow-volume curves, starting from top inspiratory level, the following indices were calculated: peak expiratory flowrate (PEFR), maximum expiratory flowrate after expelling 50\% (MEFR 50$)$ and $75 \%$ $\left(M{ }^{2} R_{25}\right)$ of FVC. In addition, in order to obtain maximum flowrates at the same absolute lung volume (even if FVC changes followed bronchodilatation) flowrates were measured at $50 \%\left(\right.$ MEFR $_{50}$ control $)$ and at $25 \%$ (MEFR (M $_{25}$ control) of the control FVC (defined as the maximum value, from at least three records, displaced during the control measurements). This approach is justified if TLC does not change (see further) and if the subject inspires each time maximally; the subjects were trained previously and coached during the measurements. Transpulmonary pressure, flowrate, and integrated flowrate were recorded on a direct writing recorder (Elema).

The procedure was as follows: normal breathing for measuring $\mathbf{R}_{\mathrm{p}}$ and $\mathrm{C}$ dyn, inspiration to $100 \%$ TLC, measurement of TGV and TLC, and finally recording of MEFR. The procedure was repeated in the same sequence after using the bronchodilator.

The results for 17 patients were finally submitted to statistical analysis; three out of 20 had to be excluded for technical reasons. A linear discriminant analysis (Fisher, 1958) was used to compare the relative value of the measured indices in the assessment of the bronchodilator effect and to estimate the amount of independent information provided by each of these indices. Their relative importance was expressed as a percentage.

\section{RESULTS}

Isoprenaline inhalation determined a statistically significant change of FVC, $R_{p}$, PEFR, MEFR $R_{50}$, MEFR $_{25}$ control (Table I). On the other hand, TLC, C dyn, end-expiratory level (before 4.421 ; after 4.221 ), tidal volume (before 0.731 ; after 0.751 ) or frequency of breathing (before 21.5 ; after 18.2 ) min) were not significantly modified.

A discriminant analysis was performed on the five indices which changed significantly following bronchodilatation. $\mathbf{R}_{p}$ and $\mathrm{MEFR}_{25}$ control demonstrated the greatest discriminative power (Table II A). When the analysis was repeated after omission of PEFR, MEFR ${ }_{50}$, and FVC, no information was lost: in fact, the $F$ value even increased (Table II B). According to this analysis, the contribution of $R_{p}$ and MEFR $_{25}$ control was of about the same importance.

\section{T A B LE I I}

DISCRIMINANT ANALYSIS COMPARING THE VALUE OF FIVE AND TWO INDICES IN ASSESSING A BRONCHODILATOR EFFECT

\begin{tabular}{|c|c|c|c|}
\hline (A) & $\begin{array}{l}\text { Regression } \\
\text { Coefficients }\end{array}$ & $\begin{array}{l}\text { Weighted } \\
\text { Values }^{1}\end{array}$ & $\begin{array}{c}\text { Percentage of } \\
\text { Sum of Weighted } \\
\text { Values }\end{array}$ \\
\hline $\begin{array}{l}\text { PEFR } \\
\text { MEFR }_{\text {so }} \\
\text { MEFR }_{25} \text { control } \\
\text { FVC }_{\mathbf{R}_{\mathbf{p}}}\end{array}$ & $\begin{array}{l}-2.18 \\
+2.07 \\
-6.93 \\
+1.00 \\
+1.38\end{array}$ & $\begin{array}{r}2 \cdot 15 \\
-1.41 \\
3.05 \\
-0.32 \\
3.25\end{array}$ & $\begin{array}{l}+31.9 \\
-21.0 \\
+45.4 \\
+4.7 \\
+48.4\end{array}$ \\
\hline
\end{tabular}

(B)

\begin{tabular}{|c|c|c|c|}
\hline $\begin{array}{l}\mathbf{M}_{\mathbf{p}} \\
\mathbf{M}_{25} \text { control }\end{array}$ & $\begin{array}{l}-4 \cdot 24 \\
+1.00\end{array}$ & $\begin{array}{l}1 \cdot 89 \\
2 \cdot 35\end{array}$ & $\begin{array}{l}44 \cdot 3 \\
55 \cdot 6\end{array}$ \\
\hline
\end{tabular}

1 The weighted value is the product of the regression coefficient obtained from the discriminant analysis with the mean difference before and after bronchodilatation.

In this study maximum values of MEFR were used while $R_{p}$ was a mean value. On the other hand, $\operatorname{MEFR}_{50}$ was the flow measured at $50 \%$ of the actual FVC. We wondered if both factors introduced a bias favouring $R_{p}$ in the discriminant analysis. Indeed, the variability of a mean value is necessarily smaller than that of a maximum value. Secondly, since the reference volume (FVC) increases after administration of isoprenaline the variations of MEFR $_{50}$ are systematically underestimated. Therefore, another analysis was performed on the mean values of $M E F R_{25}$ control, $R_{p}$, and MEFR $_{50}$ control (Table III A). Again, $R_{p}$ and

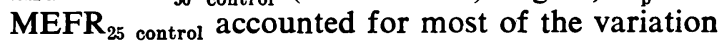
and, accordingly, we repeated the analysis for $\mathbf{R}_{p}$ and MEFR $_{25}$ control only (Table III B). This 
T A B L E I I I

DISCRIMINANT ANALYSIS COMPARING THE ABSOLUTE (A AND B) AND RELATIVE (C) VARIATIONS OF THREE OR TWO INDICES AFTER ISOPRENALINE

\begin{tabular}{|c|c|c|c|}
\hline & $\begin{array}{c}\text { Regression } \\
\text { Coefficients }\end{array}$ & $\begin{array}{l}\text { Weighted } \\
\text { Values }\end{array}$ & $\begin{array}{l}\text { Percentage of } \\
\text { Sum of Weighted } \\
\text { Values }\end{array}$ \\
\hline $\begin{array}{l}(A) \\
\text { MEFR } \\
\text { MEFro }_{25} \text { control } \\
\mathbf{R}_{\mathbf{p}}\end{array}$ & $\begin{array}{r}2 \cdot 77 \\
-9 \cdot 32 \\
1 \cdot 00\end{array}$ & $\begin{array}{r}-2 \cdot 37 \\
4 \cdot 34 \\
2 \cdot 35\end{array}$ & $\begin{array}{r}-55.1 \\
+100.5 \\
+54.6\end{array}$ \\
\hline
\end{tabular}

\begin{tabular}{|c|c|c|c|}
\hline $\begin{array}{l}(B) \\
\mathbf{M E F R}_{25} \text { controI } \\
\mathbf{R}_{\mathbf{p}}\end{array}$ & $\begin{array}{r}-4 \cdot 31 \\
+1 \cdot 00\end{array}$ & $\begin{array}{l}2.00 \\
2.35\end{array}$ & $\begin{array}{l}46 \cdot 0 \\
54 \cdot 0\end{array}$ \\
\hline
\end{tabular}

\begin{tabular}{|c|c|c|c|}
\hline $\begin{array}{l}C) \\
\text { MEFR }_{25} \text { control } \\
\mathbf{R}_{\mathbf{p}}\end{array}$ & $\begin{array}{r}-0.25 \\
+1.00\end{array}$ & $\begin{array}{l}24 \cdot 97 \\
42 \cdot 25\end{array}$ & $\begin{array}{l}37 \cdot 0 \\
63 \cdot 0\end{array}$ \\
\hline
\end{tabular}

resulted in an increase in the $F$ value. The share (in per cent) of $R_{p}$ and $M E F R_{25}$ control was the same as in the analysis of the maximum values of MEFR $_{25}$ control (Table II B).

The relative weight of $R_{p}$ and $M E F R_{25}$ control is nearly equal when the absolute changes of both indices are considered (absolute difference between initial and final values). However, when the observed variations are expressed in percentage of the initial values and the whole procedure (on the five parameters) is repeated, $R_{p}$ and MEFR $_{25}$ control again emerge as the two variables with the best discriminative power, but now the discriminant analysis seems to be more powerful (the F-test increases, not significantly, however), more information being provided by $R_{p}$ than by $\operatorname{MEFR}_{25}$ (Table III C).

\section{DISCUSSION}

Previous studies (Dautrebande et al., 1960; Lloyd and Wright, 1963; Cohen and Hale, 1965; Payne et al., 1967; Weng et al., 1969), in which the sensitivity of $\mathbf{R}_{\mathrm{aw}}$ or $\mathbf{R}_{\mathrm{p}}$ and maximum expiratory airflows were compared as indices of bronchodilatation related the maximum flows to the actual vital capacity. If the latter is also modified after bronchodilatation, the comparison of maximum flows is invalid; specifically, if the FVC increases, the change of maximum flows will be underestimated (Afschrift, Clément, Peeters, and van de
Woestijne, 1969). Secondly, lung volumes were usually measured at the mouth, so that the influence of gas compressibility was neglected. The latter factor becomes important in patients with a high total lung capacity and increased resistances, i.e., in obstructive lung disease. In addition, the maximal expiratory flowrate reported in most studies (usually maximal mid-expiratory flowrate) was a mean (measured from an expiratory spirogram) and not an instantaneous value. Flowrates at low lung volumes, which recent studies suggest are sensitive indicators of change in airways calibre, were usually not measured. These various factors result in a decrease of the sensitivity of maximum flows in comparison with airway resistance. These drawbacks were avoided in the present study by measuring various instantaneous maximum flowrates at identical plethysmographic lung volumes before and after isoprenaline.

For convenience, $R_{p}$ was used in this study instead of $R_{a w}$. We do not think that the use of $\mathbf{R}_{p}$ instead of $\mathbf{R}_{\mathrm{aw}}$ invalidates the conclusions reached. Indeed, recently, Frank, Mead, and Whittenberger (1971) showed that $R_{p}$ and $R_{a w}$ have a comparable sensitivity.

Paired $t$ tests showed that five indices (FVC, MEFR $_{50}$, MEFR $_{25}$, PEFR, and $R_{p}$ ) were significantly modified following isoprenaline. To select from different indices the one which is most sensi. tive to a given effect, one should take into account the magnitude of the mean variations, the variability and, finally, the intercorrelations of the different indices. These three factors are dealt with in a discriminant analysis (Fisher, 1958). The latter allows conclusions to be made about the independent information provided by each of the studied parameters. According to this analysis, $\mathbf{R}_{\mathrm{p}}$ and MEFR $_{25}$ control were the best indicators of the changes produced by isoprenaline. Furthermore, deletion of the other indices did not result in a loss of information.

The observation that $R_{p}$ and $\mathbf{M E F R}_{25}$ control appear to provide independent information means that if no significant change in $R_{p}$ is recorded in some patients the observed change in MEFR $_{2:}$ will probably be pronounced, and vice versa. Similar examples of a divergent response of MEFR (measured with a spirograph) and $\mathbf{R}_{\mathrm{aw}}$ following bronchodilatation were reported by Sobol, Emirgil, Wadhwani, and Sawkar (1970) and by Stein, Tanabe, Rege, and Khan (1966) in patients with chronic obstructive lung disease. Therefore, to be sure that changes following bronchodilatation will not be missed, both these indices have to be measured. Two of our patients (and one healthy subject out of five) even demonstrated a para- 
doxical reaction following the bronchodilator drug: the decrease of $\mathbf{R}_{\mathrm{aw}}$ was accompanied by a decrease in MEFR $_{25}$. Bouhuys and van de Woestijne (1971) described a similar effect in a few healthy subjects after isoprenaline. They explained this phenomenon by an increased collapsibility of large airways after isoprenaline. Irrespective of the mechanism of this finding, a decrease of maximum flows instead of the expected increase, though limited to a few patients, may limit the value of these indices in the assessment of bronchodilator therapy.

$R_{p}$ and $M E F R_{25}$ might emerge as independent factors in the analysis if the mechanisms responsible for the variations of both indices are different. It has been suggested that $\mathbf{R}_{\mathrm{aw}}$ is electively sensitive to changes in the central airways (Macklem et al., 1969), while MEFR, especially when measured at low lung volumes, is influenced to a larger extent by the calibre of peripheral airways (Macklem and Mead, 1968). However, one must be cautious in interpreting statistical results (especially percentages of the discriminant analysis) in terms of physiological mechanisms. The importance of MEFR $_{25}$ and $R_{p}$ in the discriminant analysis may be determined merely by the respective variability of these indices. This is corroborated by the observation that the value of the F-test increases when changes of resistance and maximum flows are expressed in relative values, i.e., in percentage of the initial value. This is because the magnitude of the change of both indices (following bronchodilatation) is proportional to the initial value of the latter. Expressing this change in relative value reduces its variability: the coefficient of variation of $\Delta R_{p}$ and $\triangle M E F R_{25}$ are 86.8 and $95.6 \%$, respectively, when the absolute differences are considered and 58.6 and $74.5 \%$, respectively, for their relative values. Since that reduction of variability is more pronounced for $R_{p}$, it is not surprising that the weight of $R_{p}$ increases with respect to MEFR in the discriminant analysis $(63 \%$ of total information when expressed in relative change as against $54 \%$ in absolute change). It may even be concluded that when the relative change in $R_{p}$ is considered, not much information is gained by adding the measurement of MEFR $_{25}$ : the squared Student $t$ value for $R_{p}$ is $49 \cdot 4$, which does not differ much from the F-test for both $R_{p}$ and $\operatorname{MEFR}_{25}(56 \cdot 6$ in Table III C).

Mean values of dynamic compliance did not change after isoprenaline: this measurement has no practical value in the assessment of a bronchodilator effect. Similar results were reported by Miller, Gall, and Sproule (1965) and by Ingram and O'Cain (1971).
In conclusion, the estimation of a bronchodilator effect in patients with chronic obstructive lung disease will be best appreciated by measuring two parameters, airway resistance and maximum flow at a low lung volume. The latter index appears to be less discriminatory, at least when the changes of $R_{a w}$ and MEFR $R_{25}$ are expressed in relative values.

\section{REFERENCES}

Afschrift, M., Clément, J., Peeters, R., and van de Woestijne, K. P. (1969). Maximal expiratory and inspiratory flows in patients with chronic obstructive pulmonary disease. Influence of bronchodilation. American Review of Respiratory Diseases, 100, 147.

Bouhuys, A. and van de Woestijne, K. P. (1970). Respiratory mechanics and dust exposure in byssinosis. Journal of Clinical Investigation, 49, 106.

(1971). Mechanical consequences of airway smooth muscle relaxation. Journal of Applied Physiology, 30, 670.

Cohen, A. A. and Hale, F. C. (1965). Comparative effects of isoproterenol aerosols on airway resistance in obstructive pulmonary diseases. American Journal of Medical Science, 249, 309.

Dautrebande, L., Lovejoy, F., and Constantine, H. (1960). New studies on aerosols. XI. Comparative study of some methods used for determining constriction and dilation of the airways after administering pharmacological or dust aerosols. Sensitivity of the plethysmographic method. Archives Internationales de Pharmacodynamie et de Thérapie, 129, 469.

Fisher, R. A. (1958). Statistical Methods for Research Workers, 13th edition, p. 285. Oliver and Boyd, Edinburgh.

Fletcher, C. M. (1959). Terminology, definitions, and classification of chronic pulmonary emphysema and related conditions. Thorax, 14, 286.

Frank, N. R., Mead, J., and Ferris, B. G., Jr. (1957). Mechanical behavior of the lungs in healthy elderly persons. Journal of Clinical Investigation, 36, 1680.

,-- , and Whittenberger, J. L. (1971). Comparative sensitivity of four methods for measuring changes in respiratory flow resistance in man. Journal of Applied Physiology, 31, 934.

Ingram, R. H. Jr. and O'Cain, C. F. (1971). Frequency dependence of compliance in apparently healthy smokers versus non-smokers. Bulletin de Physiopathologie Respiratoire (Nancy), 7, 195.

Lloyd, T. C. Jr. and Wright, G. W. (1963). Evaluation of methods used in detecting changes of airway resistance in man. American Review of Respiratory Diseases, 87, 529.

Macklem, P. T. and Mead, J. (1968). Factors determining maximum expiratory flow in dogs. Journal of Applied Physiology, 25, 159.

Woolcock, A. J., Hogg, J. C., Nadel, J. A., and Wilson, N. J. (1969). Partitioning of pulmonary resistance in the dog. Journal of Applied Physiology, 26, 798.

McFadden, E. R. Jr., Newton-Howes, J., and Pride, N. B. (1970). Acute effects of inhaled isoproterenol on the mechanical characteristics of the lungs in normal man. Journal of Clinical Investigation, 49, 779. 
Miller, J. M., Gall, G., and Sproule, B. J. (1965). Work of breathing before and after bronchodilators in patients with emphysema. Diseases of the Chest, 48, 458.

Payne, C. B. Jr., Chester, E. H., and Hsi, B. P. (1967). Airway responsiveness in chronic obstructive pulmonary disease. American Journal of Medicine, 42, 554.

Sobol, B. J., Emirgil, C., Wadhwani, B., and Sawkar, L. (1970). The response to bronchodilator in asthmatic subjects as assessed by pulmonary function tests. Journal of Allergy, 46, 65.
Stănescu, D. C., de Sutter, P., and van de Woestijne, K. P. (1972). Pressure-corrected flow body plethysmograph. American Review of Respiratory Diseases, 105, 304.

Stein, M., Tanabe, G., Rege, V., and Khan, M. (1966). Evaluation of spirometric methods used to assess abnormalities in airway resistance. American Review of Respiratory Diseases, 93, 257.

Weng, T. R., Featherby, E. A., Goold, J., and Levison, H. (1969). Relative sensitivity of methods for measuring airway resistance in asthmatic children. Annals of Allergy, 27, 565. 